\title{
Quando as escolas se abrem
}

OTONIEL NICCOLINI

MARIA CRISTINA ZELMANOVITS *

Educação Integral entendida como formação integral do ser humano amplia o conceito de educação, abrindo espaço para o envolvimento e responsabilidade de toda a sociedade na formação das novas gerações.

Mathias, 2006, p.12.

\section{Aos sábados e domingos, das 9 às 17 horas, 2.332 es-} colas da rede estadual de ensino de São Paulo alargam seus limites cotidianos ao assumirem o papel de centros de convivência.

Pessoas da comunidade, os próprios alunos e seus familiares são convidados a habitar espaços intencionalmente criados para o despertar de potencialidades diversas.

Atividades voltadas ao esporte, à cultura, à saúde, ao mundo do trabalho e ao festejo são planejadas e oferecidas por aproximadamente 4 mil profissionais da educação, 18.600 estudantes universitários e 10.700 voluntários. Com isso, mais de sete milhões de jovens têm tido oportunidades de compor e socializar seus saberes.

* Otoniel Niccolinı é economista, pós-graduado em relações internacionais e atua como consultor e coordenador de projetos no terceiro setor.

MARIA CRISTINA ZELMANOVITS é pedagoga e coordenadora de desenvolvimento metodológico do Cenpec. Tem atuado como assessora de projetos de literatura e artes.

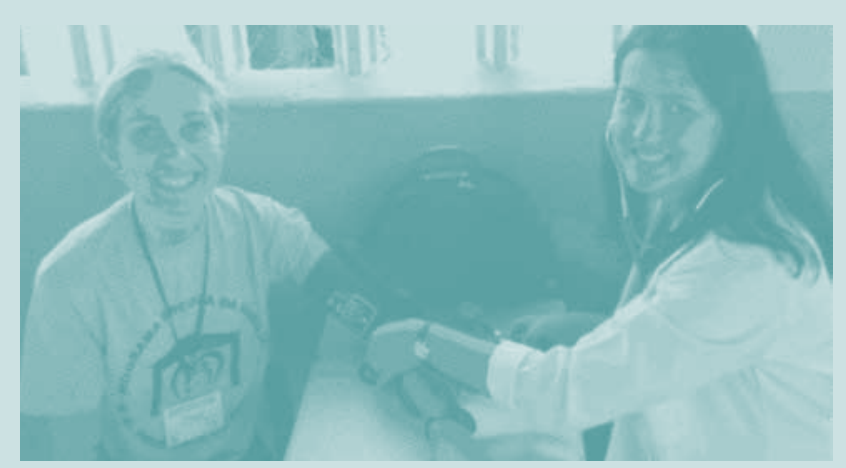

Para conhecer de perto o Programa Escola da Família, visitamos a E. E. Prudente de Moraes, incrustada no Parque da Luz ${ }^{\star}$, perto do Museu de Arte Sacra, da Pinacoteca e do Museu da Língua Portuguesa. Ou seja, um território em que parte significativa da vida cultural da cidade é tecida.

O sábado acordou chuvoso, afastando a comunidade que, em geral, participaram muito das atividades. Chegamos porvolta das 11 horas e fomos recebidos por uma equipe de universitários bolsistas bastante envolvidos com o trabalho coordenado por Cláudia Cerri.

1. Graças aos cuidadosos registros que realizam, pudemos ver a vida que por ali pulsa nos fins de semana: dança do ventre, desenho, basquete, caminhada, futebol de botão, futsal, tênis de mesa, curso de hidráulica, panificação artesanal, almoços comunitários, Lien Ch`i, ações preventivas, festa junina.

E mais, muito mais: curso de música, teatro, voleibol, ginástica localizada, dança hip hop, orientação vocacional, tapeçaria, curso de matemática, curso de manicure e pedicure, mutirões e cursos de línguas. É grande a oferta e há atividades para todas as gerações.

\section{Integração de estrangeiros}

Façamos aqui uma pequena pausa para conversar sobre os cursos de línguas: inglês e espanhol estão lado a lado com português para estrangeiros. 0 que este último nos conta? Da grande presença de estrangeiros neste território.

Habitado inicialmente por judeus, que aos poucos foram dividindo espaço com coreanos, este pedaço da região

* Jardim público mais antigo da cidade, o atual Parque da Luz (1789) foi o primeiro espaço de circulação pública de São Paulo. Depois dele, as ruas comerciais e, na década de 1960 , surgem os shoppings como alternativa - no estado, há 123 e na cidade, 51 . Abrindo aos finais de semana, as escolas oferecem opções que privilegiam a convivência em detrimento do consumo. 


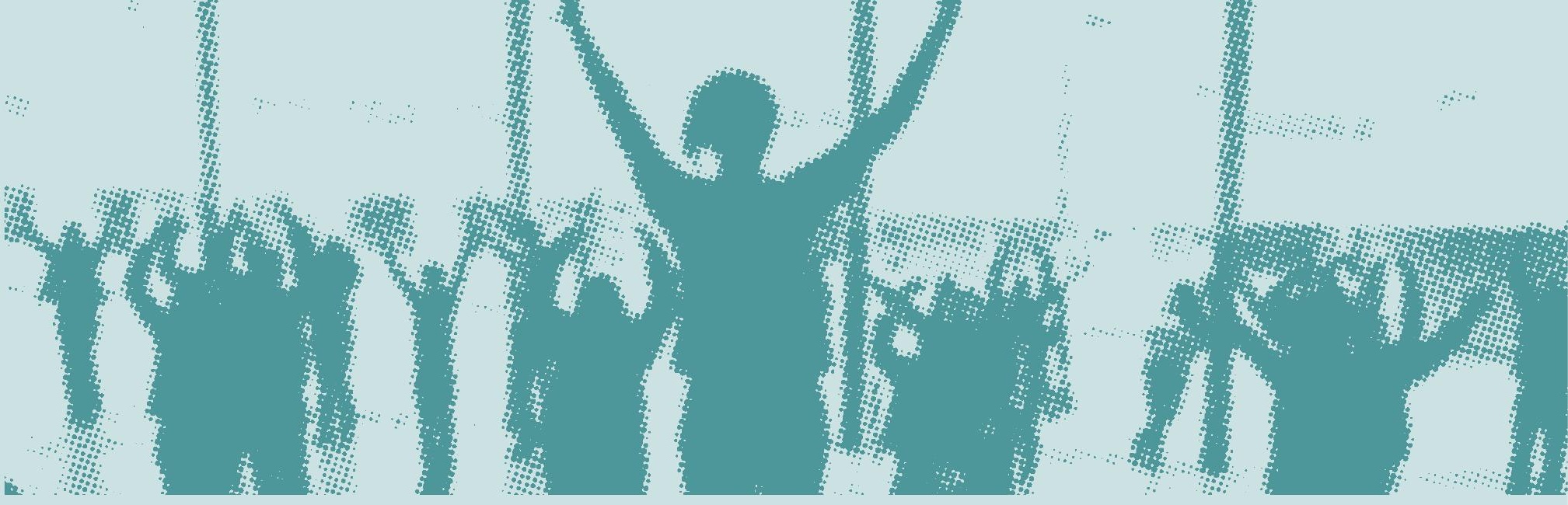

central recebe atualmente a influência dos bolivianos, que espelham condições semelhantes às de tantos outros grupos aqui nascidos: pequenas e grandes demandas de justiça; relações sociofamiliares e vínculos de pertencimento fragilizados; acesso limitado a serviços públicos; precariedade de moradia, renda e emprego.

Vivendo quase sempre fora da legalidade da cidade e da cidadania - habitam territórios clandestinos (ocupações irregulares/invasões), têm problemas com documentação, trabalham no mercado informal, não pagam impostos nem possuem seguros - forjam suas expectativas e seus valores nessas circunstâncias, conformando, em última instância, suas escolhas e adesões.

Para eles, a escola e os demais serviços públicos representam circuitos de uma cidadania reconhecida (território da legalidade), nos quais trafegam com alguma desconfiança, estranheza, como não pertencendo a eles dada à desqualificação que carregam como signo.

Na busca de novos sentidos para a função socializadora e pedagógica das escolas, o Programa Escola da Família tem demonstrado potência para se desenhar como uma das práticas de suma importância ao enfrentamento da discriminação. Ao se abrirem para acolher famílias e comunidades, envolvendo-as como sujeitos que aprendem e que também ensinam, escolas podem caminhar na direção de restaurar a confiança social perdida.

\section{Questões a superar}

\section{Mary Kawauchi, coordenadora do Escola da Família,} conta que a quantidade de relatos a respeito de brigas de alunos e depredação de patrimônio diminuiu $40 \%$ desde que o programa começou.

Embora muitas sejam as conquistas, a coordenadora lembra três aspectos que ainda pedem investimentos:

- escolas que precisam de maior adesão da comunidade;

- desigualdade na oferta de atividades (algumas escolas oferecem muitas possibilidades e outras não); e

- regiões sem universidades, o que implica poucos universitários no programa.

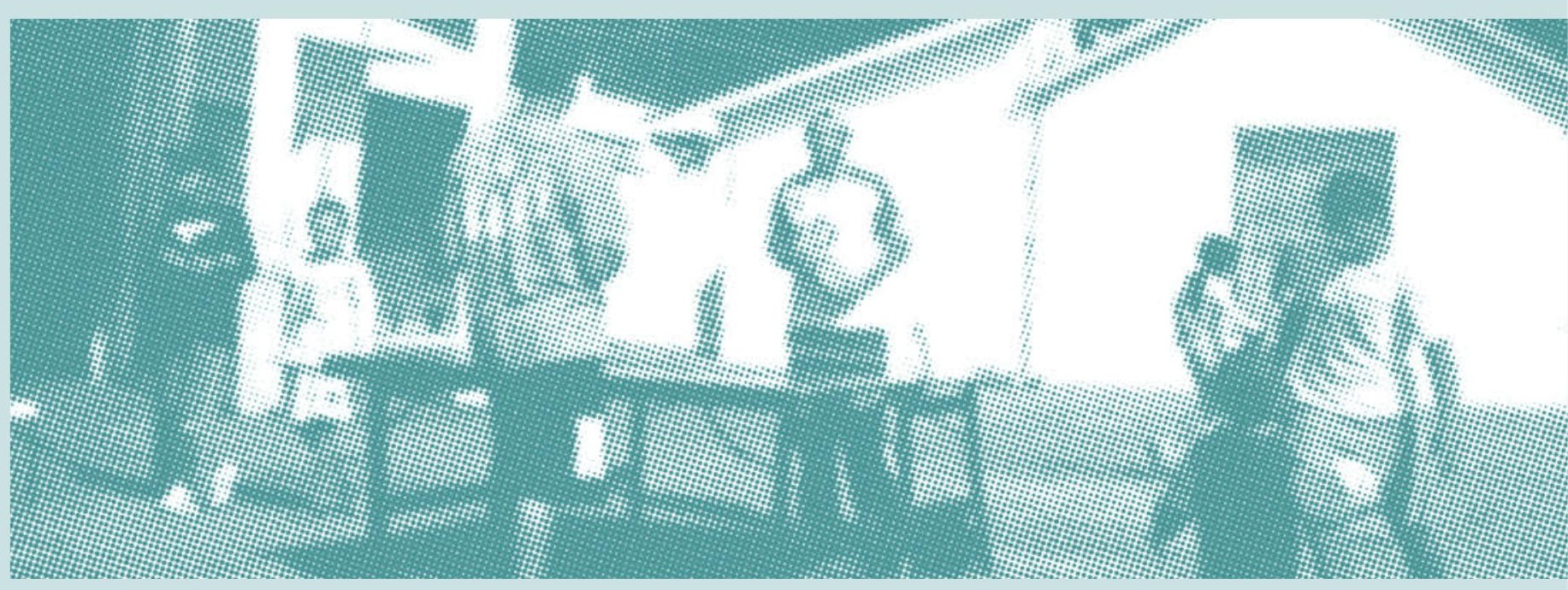




\section{PROCURAM-SE UNIVERSITÁRIOS}

Os universitários que desejam participar do programa se inscrevem. As instituições nas quais estudam precisam fazer parte do Escola da Família. O programa seleciona os que apresentam maior vulnerabilidade socioeconômica e os escolhidos decidem em qual região querem trabalhar.

Recebem isenção nas mensalidades do curso universitário - o programa paga $50 \%$ da matrícula (até o valor máximo de $\mathrm{R} \$ 267,00$ ) e a universidade arca com o restante.

Mary Kawauchi

Soma-se às dificuldades apresentadas pela coordenadora, uma outra: inicialmente o Escola da Família deveria acontecer em todas as escolas da rede, mais de 5.000 , mas hoje apenas $41 \%$ das escolas da rede estadual participam do programa.

Ana Maria Goulart, diretora da EE Dr. José Neyde César Lessa, localizada em Itapevi, conta, com pesar, que, embora a escola lotasse aos finais de semana, foi retirada do programa:

[...] fizemos um mutirão para pintar o pátio da escola com liberdade na escolha dos temas e cores. 0 resultado foi um muro absurdamente colorido e o término completo de pichações e depredações dentro da escola. Como aconteceu com a maior parte das escolas, a nossa também foi retirada do Escola da Família e hoje voltamos a conviver com as pichações.

Entre as escolas que se abrem, quisemos conhecer também uma com realidade bem diferente daquela incrustada no Parque da Luz.

Localizada no Jardim Aliança, território sem grandes opções culturais e de lazer, a E.E. Educador Paulo Freire ${ }^{1}$ tinha a única quadra da comunidade invadida nos fins de semana. Segundo o diretor Mário Soares,

Depois que passou a abrir, as coisas melhoraram muito: os alunos passaram a valorizar mais a escola e muitos pais se envolvem com as atividades. Como a região não tem locais públicos, o espaço da comunidade é a escola.

Em sua fala, Mário sintetiza uma questão fundamental: quando as escolas se abrem, há um deslocamento do olhar - de equipamento da rede de ensino para atenção ao território, suas necessidades, saberes e possibilidades de composição. A aposta é de que este movimento impacte significativamente o direito de aprender de todos e de cada um.

\section{VISITE}

Outros roteiros para se visitar com alunos e pais. Consulte:

- www.sampa.art.br/parques/jardim_daluz.php

- www.saopaulo.sp.gov.br/saopaulo/cultura/museus_sacra.htm

- www.pinacoteca.org.br/

- www.museudalinguaportuguesa.org.br/

\section{REFERÊNCIAS}

CARVALHO, Maria do Carmo Brant de. Discursos y prácticas de exclusión I: discriminación y violencia en las escuelas. Foro Internacional sobre Inclusión Educativa, Atención a la Diversidad y No Discriminación, Ciudad de México, 7, 8 e 9 de outubro de 2008.

MATHIAS, Antonio Jacinto. É preciso uma aldeia para educar uma criança. Cadernos Cenpec, São Paulo, n. 2, 2006.

\section{SITES PESQUISADOS}

www.escoladafamilia.sp.gov.br/apresentacao.html www.escoladafamilia.sp.gov.br/Escola\%20em\%20Números/CENTRO.pdf www.blognassif.blogspot.com/2007/02/parque-da-luz.html

\section{NOTA}

Para saber mais, acessar o blog: 〈http://www.eepaulofreire.blogspot.com/〉 